\title{
Optimism lowers pain: evidence of the causal status and underlying mechanisms
}

Citation for published version (APA):

Hanssen, M. M., Peters, M. L., Vlaeyen, J. W. S., Meevissen, Y. M. C., \& Vancleef, L. M. G. (2013).

Optimism lowers pain: evidence of the causal status and underlying mechanisms. Pain, 154(1), 53-58. https://doi.org/10.1016/j.pain.2012.08.006

Document status and date:

Published: 01/01/2013

DOI:

10.1016/j.pain.2012.08.006

Document Version:

Publisher's PDF, also known as Version of record

Document license:

Taverne

\section{Please check the document version of this publication:}

- A submitted manuscript is the version of the article upon submission and before peer-review. There can be important differences between the submitted version and the official published version of record.

People interested in the research are advised to contact the author for the final version of the publication, or visit the DOI to the publisher's website.

- The final author version and the galley proof are versions of the publication after peer review.

- The final published version features the final layout of the paper including the volume, issue and page numbers.

Link to publication

\footnotetext{
General rights rights.

- You may freely distribute the URL identifying the publication in the public portal. please follow below link for the End User Agreement:

www.umlib.nl/taverne-license

Take down policy

If you believe that this document breaches copyright please contact us at:

repository@maastrichtuniversity.nl

providing details and we will investigate your claim.
}

Copyright and moral rights for the publications made accessible in the public portal are retained by the authors and/or other copyright owners and it is a condition of accessing publications that users recognise and abide by the legal requirements associated with these

- Users may download and print one copy of any publication from the public portal for the purpose of private study or research.

- You may not further distribute the material or use it for any profit-making activity or commercial gain

If the publication is distributed under the terms of Article $25 \mathrm{fa}$ of the Dutch Copyright Act, indicated by the "Taverne" license above, 


\title{
Optimism lowers pain: Evidence of the causal status and underlying mechanisms
}

\author{
Marjolein M. Hanssen $^{\mathrm{a}, *}$, Madelon L. Peters ${ }^{\mathrm{a}}$, Johan W.S. Vlaeyen ${ }^{\mathrm{a}, \mathrm{b}}$, Yvo M.C. Meevissen ${ }^{\mathrm{a}}$, \\ Linda M.G. Vancleef ${ }^{a}$ \\ a Department of Clinical Psychological Science, Maastricht University, The Netherlands \\ ${ }^{\mathrm{b}}$ Research Centre for Health Psychology, University of Leuven, Belgium
}

Sponsorships or competing interests that may be relevant to content are disclosed at the end of this article.

\section{A R T I C L E I N F O}

Article history:

Received 23 April 2012

Received in revised form 20 July 2012

Accepted 9 August 2012

\section{Keywords:}

Best possible self

Cold pressor pain

Dispositional optimism

Expectation

Pain catastrophizing

\begin{abstract}
A B S T R A C T
Previous studies have demonstrated a relation between dispositional optimism and lower pain sensitivity, but the causal status of this link remains unclear. This study sought to test the causal status by experimentally inducing a temporary optimistic state by means of writing about and visualizing a future best possible self. In addition, we explored pain expectations and (situational) pain catastrophizing as possible underlying mechanisms of the link between optimism and pain. Seventy-nine university students participated in a cold pressor task (CPT). Before the CPT, half of them received the optimism manipulation and the other half a control manipulation. Induced optimism was related to lower pain intensity ratings during the CPT compared to the control group, thereby experimentally confirming causality. This effect was not explained by pain-related expectations about the task. Situational pain catastrophizing, however, did seem to mediate the relation between optimism and pain. This study is novel in that it confirms the causal status of optimism towards pain. Additionally, the results reveal that positive interventions might provide a useful alternative in reducing pain catastrophizing as an extremely relevant target in pain treatment.
\end{abstract}

(c) 2012 International Association for the Study of Pain. Published by Elsevier B.V. All rights reserved.

\section{Introduction}

Optimism has been demonstrated to be related to better psychological and physical well-being, especially in times of adversity [8,30-33]. When confronted with pain, optimists show both better adjustment $[1,2,5,28,41]$ and less pain sensitivity $[2,10,14,22]$. Despite accumulating evidence on the relationship between optimism and pain, 2 important issues still need to be resolved.

First, it is not unthinkable that less pain leads to more optimism instead of the reverse. Although longitudinal $[2,24,26]$ and laboratory [14] studies provide preliminary evidence, the causal status of optimism towards pain has not been confirmed by experimental data so far. Second, information about the mechanism or mechanisms underlying the relationship between optimism and pain is still scarce. Understanding the mechanisms of resilience can be used to stimulate adaptive responses to pain. From the literature, several possible working mechanisms can be extracted.

A first mechanism that could explain the relation between optimism and pain is the expectation of pain. Dispositional optimism has been defined as a generalized positive outcome expectancy

* Corresponding author. Address: Department of Clinical Psychological Science, Maastricht University, P.O. Box 616, 6200 MD Maastricht, The Netherlands.

E-mail address: m.hanssen@maastrichtuniversity.nl (M.M. Hanssen).
[32]. From a theoretical point of view, one could expect this generalized positive outcome expectancy to translate into more positive (or less negative) expectations about pain. The role of pain-related expectations in the experience of pain has been emphasized repeatedly $[9,20,23]$, but at least one study disconfirmed that pain expectancy is the underlying mechanism explaining the relation between optimism and pain.

A second possible mechanism underlying the optimism-pain association might be the appraisal of pain. Optimists are less inclined to process negative information [14] and tend to shift their focus to the positive features of a situation. More specifically, optimism was previously found to be negatively associated with pain catastrophizing [3,36]. Pain-specific negative appraisals [37] typically result in heightened levels of pain intensity $[18,19,40]$. A recent correlational study suggested that indeed pain catastrophizing could mediate the relationship between optimism and pain [15]. Whether optimism actually leads to less catastrophizing about upcoming pain remains to be established.

The aim of the present study was to investigate whether optimism is causally related to experimental pain sensitivity. Optimism is induced with a best possible self manipulation. This manipulation entails writing and visualizing about a positive future and was previously found to successfully induce a temporary state of optimism $[27,29]$. It is hypothesized that participants report less pain during 
and after a cold pressor task (CPT) after the best possible self exercise than after a neutral writing and visualization exercise. Additionally, the role of 2 potential explanatory mechanisms is investigated. More specifically, it is examined whether the relation between induced optimism and reported pain intensity is mediated by expected pain intensity or situational pain catastrophizing.

\section{Methods}

\subsection{Participants}

Seventy-nine students from Maastricht University between the ages of 18 and 35 years participated in this experiment. Their participation was compensated by means of course credit or financial compensation. Informed consent was obtained from each participant at the beginning of the experiment. Participants were excluded if they had prior experience with the CPT or with the writing and visualization exercise. The final sample of 79 participants consisted of 15 men and 64 women, with a mean age of 22.59 years $(\mathrm{SD}=2.86)$.

\subsection{Apparatus}

A Plexiglas bath tank of $36 \times 30 / 15 \mathrm{~cm}(\mathrm{~W} \times \mathrm{L} / \mathrm{D}$; Julabo ED-19A; Julabo Seelbach, Germany) with an open heating bath circulator was used for the CPT. The water was maintained circulating and at a constant temperature of $5^{\circ} \mathrm{C}\left( \pm 0.03^{\circ} \mathrm{C}\right)$. A plastic unit with water at room temperature $\left(20^{\circ} \mathrm{C}\right)$ was placed next to the bath tank.

\subsection{Optimism manipulation}

Participants were randomly assigned to perform either a best possible self (BPS) or a typical day (TD) writing and visualization exercise. Both exercises have successfully been used in the past as, respectively, an optimism induction or a control exercise $[27,29]$. Both exercises consisted of the following elements. First, participants were instructed to think about their BPS (experimental condition) or about a TD (control condition) for the duration of $1 \mathrm{~min}$. Next, they were requested to write about this topic uninterrupted for $15 \mathrm{~min}$. Finally, they were asked to imagine the story they wrote down as vividly as possible during $5 \mathrm{~min}$.

The instructions for the BPS exercise, which were also adopted in other studies $[27,29,35]$, were based on the pioneering work of King [21]. The instructions for the TD exercise were based on the work of Sheldon and Lyubomirsky [35]. Forty participants performed the BPS and 39 the TD exercise.

\subsection{Measures}

\subsubsection{Dispositional optimism}

To ensure that there were no baseline differences in optimism between participants before the experimental manipulation, dispositional optimism was measured with the revised Life Orientation Test (LOT-R) [33]. This questionnaire consists of 3 positively and 3 negatively framed items, such as,'In uncertain times, I usually expect the best' or 'if something can go wrong for me, it will' and 4 filler items. Items are scored on a 5-point Likert scale, ranging from $1=$ strongly disagree to $5=$ strongly agree. The LOT-R results in a total score reflecting a broad generalized positive outcome expectancy, with higher scores representing higher levels of optimism. The LOT-R has been found to be a valid and reliable measurement instrument [33]. Cronbach's alpha in the current sample was .69.

\subsection{2. (Situational) pain catastrophizing}

Pain catastrophizing was measured with the Dutch version of the Pain Catastrophizing Scale (PCS) [37,38]. Participants were asked to indicate to what extent each of 13 statements applied to them when in pain. Items such as 'I keep thinking about how much it hurts' or'I wonder whether something serious might happen' are answered on a 5-point Likert scale ranging from $0=$ not at all to 4 = always. The PCS was administered at the beginning of the experiment to check whether there were no initial differences in pain catastrophizing between participants in the 2 conditions.

After pain induction, situational pain catastrophizing (S-PCS) was assessed. The instructions of the PCS were adjusted in such a way that all items referred to the experience of the CPT [11]. Situational pain catastrophizing has been demonstrated to correlate more strongly to experimental pain responses than a trait measure of pain catastrophizing [6]. Indices for internal consistency in the current sample were $\alpha_{\mathrm{PCS}}=.89$ and $\alpha_{\mathrm{S}-\mathrm{PCS}}=.91$.

\subsubsection{Expected and experienced pain intensity ratings}

To measure expected pain intensity, participants were asked to answer the question, 'How much pain do you expect during the cold pressor task?' on a visual analogue scale (VAS) ranging from $0=$ no pain at all to $100=$ extreme pain.

Experienced pain intensity ratings were obtained by asking participants to verbally communicate with a number between 0 and 100 how much pain they felt ranging from $0=$ no pain at all to $100=$ extreme pain.

\subsubsection{Manipulation check}

2.4.4.1. Future expectations. Expectations for positive and negative future outcomes were measured with the questionnaire for Future Expectations (FEX). This scale is an adaptation of the Subjective Probability Task (SPT) [25], which has previously been demonstrated to be sensitive to an optimism manipulation $[27,29]$. The FEX consists of an equal number of positive and negative statements referring to future outcomes. These positive and negative future outcomes are equally distributed across 5 domains (Health, Professional, Social, Personal, and General).

Ten statements such as 'You will have health problems' or 'People will find you dull and boring' result in a total score for negative expectations (FEX-Neg). Ten statements such as 'You will get a lot of satisfaction out of life' or 'You will make good and lasting friendships' make up a total score for positive expectations (FEX-Pos). Participants are asked to judge the likelihood of each statement on a 7-point scale, with $1=$ not likely at all to occur to $7=$ extremely likely to occur. Internal consistency for both scales in this sample were $\alpha_{\mathrm{FEX}-\mathrm{Pos}}=.80$ and $\alpha_{\mathrm{FEX}-\mathrm{Neg}}=.85$ for the pre-manipulation measurement and $\alpha_{\mathrm{FEX}-\mathrm{Pos}}=.87$ and $\alpha_{\mathrm{FEX}-\mathrm{Neg}}=.89$ in the post-manipulation phase.

2.4.4.2. Positive and negative mood. State mood was measured on a VAS ranging from $0=$ not at all to $100=$ extremely. Responses to the questions 'How positive are you feeling at this moment?' and 'How negative are you feeling at this moment?' resulted in a state measure for positive mood (MOOD-Pos) and negative mood (MOOD-Neg). The measurement of affect was used as a secondary manipulation check. Previous studies have found effects of the BPS manipulation on both future expectations and (positive) affect [27,29].

2.4.4.3. Quality of writing and imagery. Two VAS scales ranging from 0 to 100 were administered as a check for possible qualitative differences between the BPS and TD exercise [29]. Participants were asked to answer the following questions: 'How well could you imagine yourself in the situation you described in your writing?' (not at all-extremely well) and 'How vivid were the pictures you imagined?' (not vivid at all-very vivid).

\subsection{Procedure}

Participants were recruited for participation in a study examining the influence of visualization on pain during a CPT. At their 
arrival at the laboratory, participants were welcomed and informed consent forms were signed. Baseline measures (LOT-R, PCS, VAS Mood Before Manipulation, and FEX Before Manipulation) were obtained and participants were randomly assigned to the BPS or the TD condition. Subsequently, the writing and visualization exercise was explained. Participants started out with thinking about their topic for $1 \mathrm{~min}$. Thereafter, the experimenter left the room for the duration of the writing part $(15 \mathrm{~min})$ to set the participant at ease during the exercise. When the experimenter came back in, she instructed the participant to visualize about the written stories for another $5 \mathrm{~min}$. After the writing and visualization exercise, participants completed the post-manipulation measures of future expectations and mood, as well as the control measure concerning the quality of the writing and imagery. Participants then received detailed instructions about the 1-min CPT and the pain rating procedure. They were also instructed about the correct manner of immersing their nondominant hand in the water, which is immersed up to the level of the wrist with a horizontally stretched-out hand that is not in contact with the bottom of the container. Ratings of expected pain intensity were obtained before participants immersed their nondominant hand in a room temperature container $\left(20^{\circ} \mathrm{C}\right)$. The latter was done to acquire equal skin temperature. Next, the CPT was conducted and the researcher prompted pain intensity ratings at 20,40 , and $60 \mathrm{~s}$ during the immersion and at $20 \mathrm{~s}$ after participants withdrew their hand from the cold water. Participants who were unable to complete the 1min immersion were asked to provide a pain intensity rating the moment they withdrew their hand (as an end rating) and $20 \mathrm{~s}$ later for the postimmersion rating. After termination of the CPT, participants completed the VAS Mood after immersion and the S-PCS. Participants were compensated and thanked for their participation.

\subsection{Statistical analyses}

Mean and standard deviation were calculated for baseline measures (LOT-R, PCS Trait, FEX-Pos Before Manipulation, FEXNeg Before Manipulation, MOOD-Pos Before Manipulation and MOOD-Neg Before Manipulation) for the 2 conditions.

Independent samples $t$ tests and a chi-square test were used for the randomisation check on sex, age, and baseline measures. Pearson correlations were calculated to represent the associations between the baseline measures.

A manipulation check was performed on post-minus premeasurement difference scores of negative and positive future expectations and state mood measures ( $\triangle$ FEX-Pos, $\Delta$ FEX-Neg, $\triangle M O O D-P o s$, and $\triangle$ MOOD-Neg). Independent samples $t$ tests were used to detect significant differences in change between the conditions. Differences between quality of writing and visualization were also investigated by independent samples $t$ tests.

Before analysing data on pain intensity during and after immersion, missing data were replaced. For the pain ratings during immersion, the last value put forward method was used. All missing values during immersion were caused by early hand withdrawal. Eleven participants did not complete the 1-min immersion (range 14-55 s). These participants provided a pain intensity rating immediately upon hand withdrawal from the cold water. This rating score was imputed at every subsequent missing value during the immersion phase. One postimmersion score was missing in the dataset and was replaced by means of a linear regression equation that was based on the 3 during-immersion ratings of the concerning condition.

The influence of induced optimism on pain intensity ratings during immersion was tested with a repeated-measures ANOVA with time (20, 40 and $60 \mathrm{~s}$ ) as a within-subject factor, and condition (BPS and TD) as a between-subject factor. The effect of induced optimism (BPS and TD) on pain intensity ratings after immersion was examined with an independent samples $t$ test.

On the basis of results of the preceding analyses, mediation was only tested for pain reports during immersion. Preliminary analyses were performed to explore mediation effects of expected pain intensity and situational pain catastrophizing. Independent samples $t$ tests were performed to test if these candidate mediators differed significantly between conditions. Next, relations between candidate mediators and reported pain intensity during immersion were explored with Pearson correlation coefficients. Mediation analyses were then conducted for each candidate mediator that was found to differ significantly between the BPS and TD condition.

Multiple regression analyses were performed following the guidelines of Baron and Kenny [4]. As a first step in testing mediation, it was tested whether condition correlated with the mean pain intensity rating during immersion. As a second step in testing mediation, the relation between condition and the candidate mediator was tested. As a third step in testing mediation, both condition and mediator were entered in the regression analysis as predictors of reported pain during immersion. Mediation was confirmed if the first 2 steps were met and if the condition effect diminished when controlled for the mediator.

\section{Results}

\subsection{Baseline descriptives}

Mean scores and standard deviations for both conditions separately are listed in Table 1 . Independent samples $t$ tests indicated that there were no significant differences between the 2 conditions for these baseline measurements.

In addition, no significant differences were found between both conditions with regard to age $(t(77)=-.45 ; P=.65)$ and sex $\left(\chi^{2}(1,79)=.84 ; P=.36\right)$.

Table 1 also provides correlations between baseline scores of optimism, pain catastrophizing, positive future expectations, negative future expectations, positive mood, and negative mood. All

Table 1

Means, standard deviations (SD), randomisation check, and correlations between baseline variables.

\begin{tabular}{|c|c|c|c|c|c|c|c|c|}
\hline \multirow[t]{2}{*}{ Variable } & \multicolumn{3}{|l|}{ Mean (SD) } & \multicolumn{5}{|c|}{ Correlation } \\
\hline & Total $(n=79)$ & BPS $(n=40)$ & $\mathrm{TD}(n=39)$ & 1 & 2 & 3 & 4 & 5 \\
\hline 1. LOT-R & $22.23(3.10)$ & $22.35(3.33)$ & $22.10(2.87)$ & & & & & \\
\hline 2. PCS & $16.25(8.02)$ & $16.07(9.40)$ & $16.44(6.43)$ & $-.40^{* *}$ & & & & \\
\hline 3. FEX-Pos Before Manipulation & $54.47(5.40)$ & $54.95(5.39)$ & $53.97(5.45)$ & $.47^{* *}$ & $-.26^{*}$ & & & \\
\hline 4. FEX-Neg Before Manipulation & $31.18(8.55)$ & $29.90(7.70)$ & $32.49(9.26)$ & $-.59^{* *}$ & $.44^{* *}$ & $-.58^{* *}$ & & \\
\hline 5. MOOD-Pos Before Manipulation & $73.63(13.54)$ & $73.78(13.17)$ & $73.49(14.07)$ & $.36^{* *}$ & $-.28^{*}$ & $.43^{* *}$ & $-.42^{* *}$ & \\
\hline 6. MOOD-Neg Before Manipulation & $21.35(16.93)$ & $19.93(16.41)$ & $22.82(17.55)$ & $-.28^{* *}$ & $.27^{*}$ & $-.43^{* *}$ & $.37^{* *}$ & $-.71^{* * *}$ \\
\hline
\end{tabular}

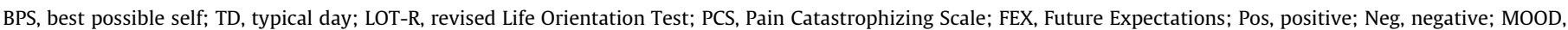
state measure for mood.

* $P<.05$.

${ }^{* *} P<.01$. 
Table 2

Means, standard deviations (SD), and significant differences between conditions of manipulation check variables.

\begin{tabular}{lccc}
\hline Variable & \multicolumn{2}{l}{ Mean (SD) } & $t$ value \\
\cline { 2 - 4 } & BPS & TD & \\
\hline FEX-Pos change & $2.63(2 . c 83)$ & $-.18(2.75)$ & $4.47^{* *}$ \\
FEX-Neg change & $-4.70(4.30)$ & $-1.03(2.80)$ & $-4.51^{* *}$ \\
MOOD-Pos change & $9.70(9.24)$ & $2.36(11.60)$ & $3.12^{* *}$ \\
MOOD-Neg change & $-5.35(10.03)$ & $-.62(16.21)$ & 1.60 \\
\hline
\end{tabular}

BPS, best possible self; TD, typical day; FEX, Future Expectations; Pos, positive; Neg, negative; MOOD, state measure for mood. ${ }^{*} P<.05$.

*** $P<.01$.

variables are found to correlate significantly in the expected direction.

\subsection{Manipulation check}

Independent samples $t$ tests were performed with change (post minus pre) scores of FEX-Pos, FEX-Neg, MOOD-Pos, and MOOD-Neg to examine the effect of the optimism manipulation. As shown in Table 2, the BPS manipulation led to significantly larger changes in positive and negative future expectations, as well as on positive mood, compared to the TD manipulation. (Similar results were obtained when the manipulation check was performed using ANCOVAs with each post-manipulation measure as the dependent variable and condition and pre-manipulation measure as independent variables.)

Additional independent samples $t$ test were performed to control for possible qualitative (in contrast to content-related) differences between BPS and TD manipulation. With mean scores of $77.24(\mathrm{SD}=15.17)$ in the BPS condition and $79.44(\mathrm{SD}=21.29)$ in the TD condition, no significant difference in quality of imagination during the writing process was found $(\mathrm{t}(77)=-.52 ; P=-.60)$. Also, with regard to the vividness of the visualization there was no significant difference $(\mathrm{t}(77)=-1.19 ; \quad P=.24)$ between the BPS
$(M=67.63, \quad \mathrm{SD}=23.48)$ and the TD condition $(M=73.49$ $\mathrm{SD}=19.96)$.

\subsection{Influence of induced optimism on pain}

Fig. 1 presents mean pain intensity ratings during and after immersion in both the BPS and the TD condition. As presented in Fig. 1, the mean scores of reported pain intensity are systematically lower in the BPS condition (with $M(20 \mathrm{~s})=46.40, S D=21.52$; $M(40 \mathrm{~s})=60.15, \mathrm{SD}=23.88 ; M(60 \mathrm{~s})=66.09, \mathrm{SD}=25.14$ and $M(20 \mathrm{~s}$ post) $=35.15, \mathrm{SD}=24.54$ ) compared to the TD condition (with $M(20 \mathrm{~s})=53.59, \quad \mathrm{SD}=20.80 ; \quad M(40 \mathrm{~s})=70.13, \quad \mathrm{SD}=17.45$ $M(60 \mathrm{~s})=80.59, \mathrm{SD}=15.74$ and $M(20 \mathrm{~s}$ post $)=45.39, \mathrm{SD}=21.44)$. Differences between conditions were tested for during immersion and postimmersion ratings separately.

A repeated-measures ANOVA with a Greenhouse-Geisser correction revealed a significant Time effect $(F(1,77)=93.39, P<.01)$ for the pain reports during immersion. In support of our main hypothesis, a significant Condition effect $(F(1,77)=6.04, P<.05)$ indicates that participants in the BPS condition had significantly lower pain intensity ratings across all 3 time points than participants in the TD condition. The absence of a Time $\times$ Condition interaction $(F(1,77)=2.27, P=.124)$ indicates that the differences between the BPS and TD groups did not vary as a function of time.

Pain intensity after immersion was significantly lower in the BPS condition compared to the TD condition $(t(77)=1.97, P=.05)$.

\subsection{Mediation of the relation between optimism and reported pain} intensity

Reported pain intensity significantly differed between conditions during, but not after immersion. Therefore, mediation was tested for this period only. Moreover, because no interaction effect with time was found, further analyses were based on the mean of pain intensity ratings during immersion, with $M(\mathrm{SD})=57.55$ (21.15) in the BPS condition and $M(\mathrm{SD})=68.10(16.70)$ in the TD condition.

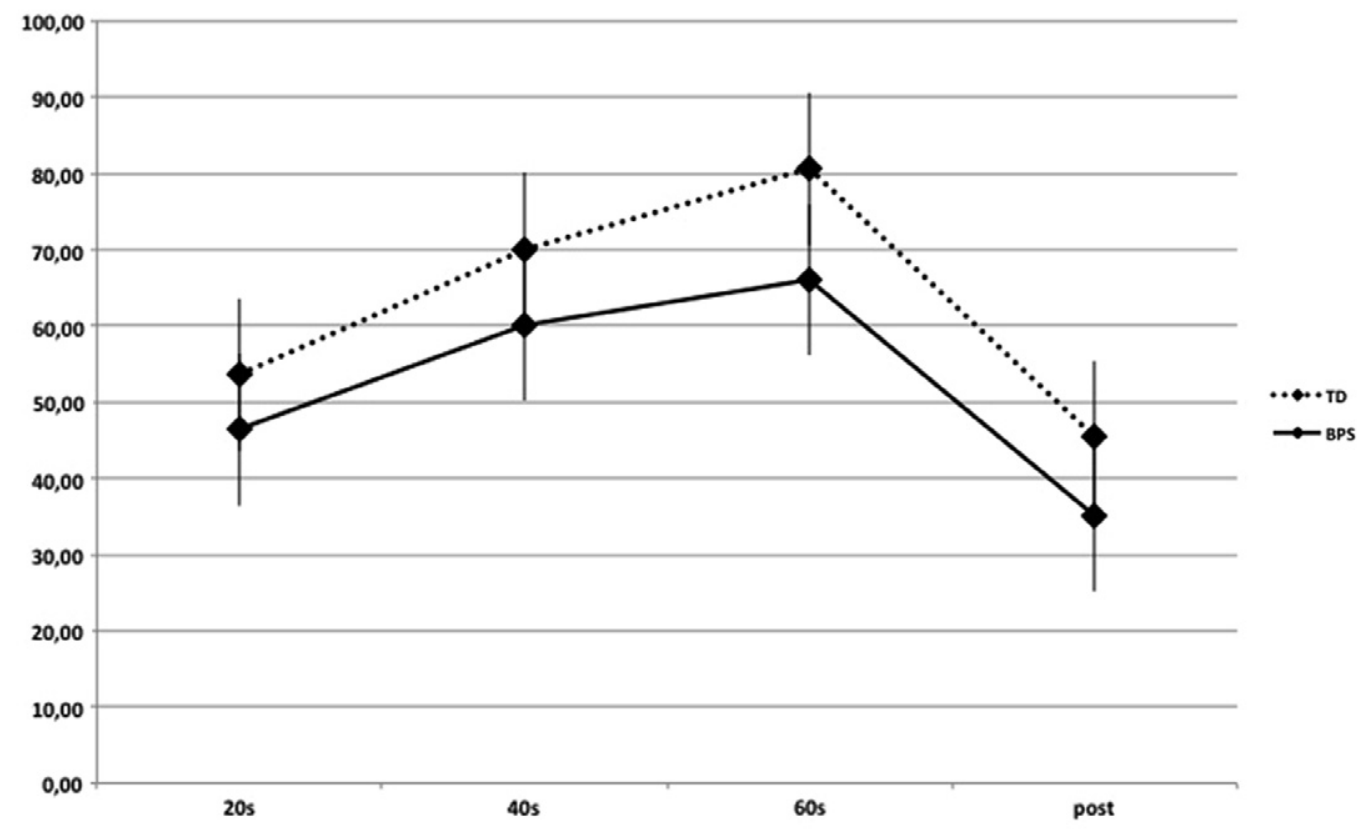

Fig. 1. Pain intensity ratings at 20,40 , and 60 s during and $20 \mathrm{~s}$ after immersion in the BPS and TD conditions. 
Table 3

Means, standard deviations (SD), and results of independent samples $t$ tests and correlation analyses for mean pain intensity during immersion and candidate mediators.

\begin{tabular}{|c|c|c|c|c|c|}
\hline \multirow[t]{2}{*}{ Mediator } & \multicolumn{2}{|l|}{ Mean (SD) } & \multirow[t]{2}{*}{$t$ value } & \multicolumn{2}{|c|}{ Correlation } \\
\hline & BPS & TD & & 1 & 2 \\
\hline $\begin{array}{l}\text { 1. Reported pain } \\
\text { intensity during } \\
\text { immersion }\end{array}$ & $57.55(21.15)$ & $68.10(16.70)$ & $-2.46^{*}$ & & \\
\hline $\begin{array}{l}\text { 2. Expected pain } \\
\text { intensity }\end{array}$ & $48.03(24.66)$ & $51.18(21.98)$ & -.60 & $.30^{* *}$ & \\
\hline $\begin{array}{l}\text { 3. Situational pain } \\
\text { catastrophizing }\end{array}$ & $14.88(19.31)$ & $19.31(8.67)$ & $-2.03^{*}$ & $.60^{* *}$ & $.31^{* *}$ \\
\hline
\end{tabular}

Table 3 shows the results of independent samples $t$ tests and correlation analyses for situational pain catastrophizing, expected pain intensity, and mean pain intensity during immersion.

Regression analyses were performed to test mediation for situational pain catastrophizing because only this variable significantly differed between the BPS and TD condition. First, condition was significantly related to mean pain intensity ratings during immersion $(\beta=.27 ; t=2.46 ; P<.05)$. Second, condition was significantly related to situational pain catastrophizing $(\beta=.23 ; t=2.03$; $P<.05)$. As a third step in testing mediation, both condition and mediator (S-PCS) were added to condition as predictor of mean pain intensity ratings during immersion.

The last regression analysis revealed situational catastrophizing as a strong predictor of reported pain intensity $(\beta=.57 ; t=6.17$; $P<.01$ ), reducing the influence of condition on pain intensity to nonsignificance $(\beta=.14 ; t=1.53 ; P>.05)$, thereby confirming mediation. A Sobel test indicated that the reduction in the beta coefficients is borderline significant $(S=1.93 ; S E=2.59 ; P=0.053)$.

\section{Discussion}

The aim of this study was to examine 2 important issues, namely the causal status of optimism towards pain and the potential underlying mechanisms of this relation. By means of a BPS manipulation, a temporary state of optimism was successfully induced in half of the participants. This manipulation led to lower pain intensity ratings during a CPT compared to a control manipulation, confirming the hypothesized causal relation between optimism and pain. Furthermore, situational pain catastrophizing seemed to mediate the relation between induced optimism and pain during the CPT.

This study provides evidence for the causal status of optimism towards pain. Previous laboratory and longitudinal studies confirmed the relation between optimism and pain $[2,10,14,24,26]$. Although previous studies provided preliminary evidence for the causal status of optimism towards pain-related outcomes, to our knowledge, no study to date has used an experimental design to confirm causality. In this study, we therefore took it one step further and experimentally induced optimism in half of the participants to investigate the direct effect on pain in a laboratorycontrolled situation. In line with our hypothesis, induced optimism led to lower pain intensity ratings during the CPT.

In order to induce optimism, we used a writing and visualization exercise that had proved to be successful in previous studies in inducing a temporary and even prolonged state of optimism $[27,29]$. In line with these studies, the manipulation significantly altered future expectations and positive mood. In this study, future expectations were measured with FEX, an adaptation of the SPT that was previously used as a measure of momentary optimism.
In contrast with SPT, FEX consists of an equal amount of positive and negative statement that are balanced over 5 domains (Health, Professional, Social, Personal, and General). Furthermore, in our judgment, the transformation led to a higher probability of occurrence of especially the negative items. Interestingly, dispositional optimism significantly correlates to both positive and negative future expectations as measured with the FEX, in contrast to the single correlation with positive expectations as measured by the SPT that was found by Peters et al. [29].

Second, we were not only interested in the causal status of optimism, but we also wanted to examine the underlying mechanism in the optimism-pain association. Two processes-expectation and appraisal towards pain-were investigated. More specifically, expected pain intensity and situational pain catastrophizing were tested as possible mediators in the relation between induced optimism and pain ratings during a CPT.

The first proposed candidate for mediation was expected pain intensity. The conceptualisation of dispositional optimism as a generalized positive outcome expectancy [32] and the previously established links between expected and perceived pain intensity $[9,20,23]$ raised the possibility of a mediation model with expected pain intensity. However, this model was disconfirmed in our previous study. Also in the present study, expected pain intensity was found to be associated with pain intensity ratings during immersion, but induced optimism did not influence expectations, again disconfirming the role of expected pain intensity as a mediator.

A second mechanism that was investigated for the optimismpain association was negative appraisal. Negative appraisals of pain as measured with the S-PCS seemed to mediate the relation between optimism and pain rating during immersion. This finding is in line with the finding that optimists do not seem to focus on negative information [14,16,17,34,39]. Moreover, our data confirm and strengthen previous findings $[3,15,36]$ by demonstrating that induced optimism directly leads to less situational pain catastrophizing during a CPT. Previously, it has been postulated that positive emotions can counter downward spirals of negativity $[12,13]$. In a similar vein, our results reveal that general positive appraisals can counter pain-specific negative appraisals.

This study has limitations that should be noted. Firstly, in this study, pain reports were used as a measure of pain experience. Although reported pain intensity is widely used as a measure for the experience of pain, a behavioural measure would strengthen these findings. Secondly, 11 participants did not complete the CPT, and therefore the data for the missing time points of these participants were imputed. Although results with and without imputed data yielded the same results, this should be borne in mind in interpreting the results. Thirdly, only the short-term effect of the optimism manipulation on experimentally induced pain was measured in this study. Future research should further investigate long-term effects as well as the influence of optimism on continuing processes in response to chronic pain. Lastly, only negative (mediation and outcome) variables were included in this study. The influence of optimism on adaptive (in addition to less maladaptive) processes could contribute to understanding the strength of optimism.

This study is of substantial theoretical and clinical importance. To our knowledge, this study is the first to support the causal status of optimism towards pain in a laboratory-controlled experimental setting. The results stress that positive interventions might provide a useful alternative in reducing pain catastrophizing as a highly relevant target in pain treatment. The first results of interventions aimed at building resilience in chronic pain patients are promising and seem to be able to reduce the negative impact of pain [7]. Finally, this study demonstrates that the BPS writing and visualization exercise seems to provide a reliable paradigm and new opportunities for the study of optimism in the context of pain. 


\section{Conflict of interest statement}

The authors report no conflict of interest.

\section{Acknowledgements}

We thank Katharina Pittner, Anne Schraa, Henrietta Steinhart, and Anne van der Vorst for their valuable input in this study and for their assistance in the data collection. This study was supported by a grant from the Netherlands Foundation of Scientific Research.

\section{References}

[1] Affleck G, Tennen H, Zautra A, Urrows S, Abeles M, Karoly P. Women's pursuit of personal goals in daily life with fibromyalgia: a value-expectancy analysis. J Consult Clin Psychol 2001;69:587-96.

[2] Allison PJ, Guichard C, Gilain L. A prospective investigation of dispositional optimism as a predictor of health-related quality of life in head and neck cancer patients. Qual Life Res 2000;9:951-60.

[3] Bargiel-Matusiewicz K, Krzyszkowska A. Dispositional optimism and coping with pain. Eur J Med Res 2009;14:271-4.

[4] Baron RM, Kenny DA. The moderator-mediator variable distinction in social psychological research: conceptual, strategic, and statistical considerations. J Pers Soc Psychol 1986;51:1173-82.

[5] Brenes GA, Rapp SR, Rejeski WJ, Miller ME. Do optimism and pessimism predict physical functioning? J Behav Med 2002;25:219-31.

[6] Campbell CM, Kronfli T, Buenaver LF, Smith MT, Berna C, Haythornthwaite JA, Edwards RR. Situational versus dispositional measurement of catastrophizing: associations with pain responses in multiple samples. J Pain 2010;11:e2.

[7] Carson JW, Keefe FJ, Lynch TR, Carson KM, Goli V, Fras AM, Thorp SR. Lovingkindness meditation for chronic low back pain: results from a pilot trial. J Holist Nurs 2005;23:287-304.

[8] Carver CS, Scheier MF, Segerstrom SC. Optimism. Clin Psychol Rev 2010; 30:879-89.

[9] Colloca L, Sigaudo M, Benedetti F. The role of learning in nocebo and placebo effects. PAIN ${ }^{\circledR} 2008 ; 136: 211-8$

[10] Costello NL, Bragdon EE, Light KC, Sigurdsson A, Bunting S, Grewen K, Maixner W. Temporomandibular disorder and optimism: relationships to ischemic pain sensitivity and interleukin-6. PAIN ${ }^{\circledR} 2002 ; 100: 99-110$.

[11] Fabian LA, McGuire L, Goodin BR, Edwards RR. Ethnicity, catastrophizing, and qualities of the pain experience. Pain Med 2011;12:314-21.

[12] Fredrickson BL. The role of positive emotions in positive psychology. The broaden-and-build theory of positive emotions. Am Psychologist 2001; $56: 218-26$.

[13] Garland EL, Fredrickson B, Kring AM, Johnson DP, Meyer PS, Penn DL. Upward spirals of positive emotions counter downward spirals of negativity: insights from the broaden-and-build theory and affective neuroscience on the treatment of emotion dysfunctions and deficits in psychopathology. Clin Psychol Rev 2010;30:849-64.

[14] Geers AL, Wellman JA, Helfer SG, Fowler SL, France CR. Dispositional optimism and thoughts of well-being determine sensitivity to an experimental pain task. Ann Behav Med 2008;36:304-13.

[15] Hood A, Pulvers K, Carrillo J, Merchant G, Thomas M. Positive traits linked to less pain through lower pain catastrophizing. Pers Individ Dif 2012:52:401-5.

[16] Isaacowitz DM. The gaze of the optimist. Pers Soc Psychol Bull 2005; 31:407-15.

[17] Karademas EC, Kafetsios K, Sideridis GD. Optimism, self-efficacy and information processing of threat- and well-being related information. Stress Health 2007;23:285-94.

[18] Keefe FJ, Lumley M, Anderson T, Lynch T, Studts JL, Carson KL. Pain and emotion: new research directions. J Clin Psychol 2001;57:587-607.
[19] Keefe FJ, Rumble ME, Scipio CD, Giordano LA, Perri LM. Psychological aspects of persistent pain: current state of the science. J Pain 2004;5:195-211.

[20] Keltner JR, Furst A, Fan C, Redfern R, Inglis B, Fields HL. Isolating the modulatory effect of expectation on pain transmission: a functional magnetic resonance imaging study. J Neurosci 2006;26:4437-43.

[21] King LA. The health benefits of writing about life goals. Pers Soc Psychol Bull 2001;27:798-807.

[22] Kurtz ME, Kurtz JC, Given CW, Given BA. Patient optimism and mastery-do they play a role in cancer patients' management of pain and fatigue? J Pain Symptom Manage 2008;36:1-10.

[23] Lorenz J, Hauck M, Paur RC, Nakamura Y, Zimmermann R, Bromm B, Engel AK. Cortical correlates of false expectations during pain intensity judgments-a possible manifestation of placebo/nocebo cognitions. Brain Behav Immun 2005;19:283-95.

[24] Luger T, Cotter KA, Sherman AM. It's all in how you view it: pessimism, social relations, and life satisfaction in older adults with osteoarthritis. Aging Ment Health 2009;13:635-47.

[25] MacLeod AK. Affect, emotional disorder, and future-directed thinking. Cogn Emot 1996;10:69-86.

[26] Mahler HIM, Kulik JA. Optimism, pessimism and recovery from coronary bypass surgery: prediction of affect, pain and functional status. Psychol Health Med 2000;5:347-58.

[27] Meevissen YM, Peters ML, Alberts HJ. Become more optimistic by imagining a best possible self: effects of a two week intervention. J Behav Ther Exp Psychiatry 2011;42:371-8.

[28] Novy DM, Nelson DV, Hetzel RD, Squitieri P, Kennington M. Coping with chronic pain: sources of intrinsic and contextual variability. J Behav Med 1998; 21:19-34.

[29] Peters ML, Flink IK, Boersma K, Linton SJ. Manipulating optimism: can imagining a best possible self be used to increase positive future expectancies?. J Posit Psychol 2010;5:204-11.

[30] Rasmussen HN, Scheier MF, Greenhouse JB. Optimism and physical health: meta-analytic review. Ann Behav Med 2009;37:239-56.

[31] Scheier MF, Carver CS. Effects of optimism on psychological and physical wellbeing: theoretical overview and empirical update. Cogn Ther Res 1992;16:201-28.

[32] Scheier MF, Carver CS. Optimism, coping, and health: assessment and implications of generalized outcome expectancies. Health Psychol 1985; 4:219-47.

[33] Scheier MF, Carver CS, Bridges MW. Distinguishing optimism from neuroticism (and trait anxiety, self-mastery, and self-esteem): a reevaluation of the Life Orientation Test. J Pers Soc Psychol 1994;67:1063-78.

[34] Segerstrom SC. Optimism and attentional bias for negative and positive stimuli. Pers Soc Psychol Bull 2001;27:1334-43.

[35] Sheldon KM, Lyubomirsky S. How to increase and sustain positive emotion: the effects of expressing gratitude and visualizing best possible selves. J Posit Psychol 2006;1:73-82.

[36] Sinclair VG. Predictors of pain catastrophizing in women with rheumatoid arthritis. Arch Psychiatr Nurs 2001;15:279-88.

[37] Sullivan MJ, Bishop SR, Pivik J. The Pain Catastrophizing Scale: development and validation. Psychol Assess 1995;7:524-32.

[38] Van Damme S, Crombez G, Bijttebier P, Goubert L, Van Houdenhove B. A confirmatory factor analysis of the Pain Catastrophizing Scale: invariant factor structure across clinical and non-clinical populations. PAIN ${ }^{\circledR} 2002 ; 96: 319-24$

[39] Vancleef LM, Peters ML. Examining content specificity of negative interpretation biases with the Body Sensations Interpretation Questionnaire (BSIQ). J Anxiety Disord 2008;22:401-15.

[40] Vlaeyen JW, Hanssen M, Goubert L, Vervoort T, Peters M, van Breukelen G, Sullivan MJ, Morley S. Threat of pain influences social context effects on verbal pain report and facial expression. Behav Res Ther 2009;47:774-82.

[41] Wong WS, Fielding R. Quality of life and pain in Chinese lung cancer patients: is optimism a moderator or mediator? Qual Life Res 2007;16:53-63. 